\title{
1 Estimation of Paleo-firing Temperatures Using Luminescence Signals for the Volcanic Lava Baked Layer in Datong, China

\author{
Zhe Liu ${ }^{\mathrm{a}}$, Hua Zhao ${ }^{\mathrm{a}}$, Cheng-Min Wang ${ }^{\mathrm{a}}$, Sheng-Hua $\mathrm{Li}^{\mathrm{a}, \mathrm{b}}$ \\ ${ }^{a}$ Institute of Hydrogeology and Environmental Geology, CAGS, Shijiazhuang 050061, China \\ *Corresponding author. Tel: +86 31167598578. E-mail address: zhaohua65@163.com (Hua Zhao)
} \\ ${ }^{\boldsymbol{b}}$ Department of Earth Sciences, The University of Hong Kong, Pokfulam Road, Hong Kong, China
}

Abstract: Eight paleo-fired samples from the baked layer in different depths under the lava and one unfired sample were collected from Datong, China. Fine quartz grains $(4-11 \mu \mathrm{m})$ from samples were used for probing into relationship between luminescence signals and paleo-firing temperatures. Findings from the re-firing experiments indicated that using thermoluminescence (TL) and optically stimulated luminescence (OSL) sensitivity changes could estimate the paleo-firing temperatures of samples: (1) $110{ }^{\circ} \mathrm{C}$ TL sensitivity change rate against the re-firing temperature can tell whether the sample has been fired to temperatures above $500{ }^{\circ} \mathrm{C}$ or not; (2) 150

${ }^{\circ} \mathrm{C}$ TL sensitivity against the re-firing temperature can indicate whether the sample has been fired to temperatures above $900{ }^{\circ} \mathrm{C}$ or not;

(3) the more specific paleo-firing temperatures can be estimated by comparing the ratio of OSL and $150{ }^{\circ} \mathrm{C}$ TL sensitivities against re-firing temperatures. Results showed that the paleo-firing temperatures of the eight lava-baked samples decreased exponentially with the distance from the lava. Based on the estimated temperature profile, the temperature of the lava was estimated to be about $1100{ }^{\circ} \mathrm{C}$.

Key words: Datong volcano; baked layer; temperature; luminescence; sensitivity; fine grain quartz

\section{Introduction}

Deducing the temperatures of the lava flows is of great significance for analyzing the flowing process of lava (Griffiths, 2000; Pinkerton et al., 2002), which helps to define the extents and degree affected by volcanoes. The paleo-firing temperature estimation of the baked layer beneath the lava can provide a possibility for assessing the temperature of the lava above. The estimation of paleo-firing temperatures also provides the information of the 
22 degree of zeroing for heated samples, which is essential for luminescence dating.

23 Several studies showed that luminescence sensitivity changes of quartz were related to the thermal history

24 (Bøtter-Jensen et al., 1995; Wintle and Murray, 1999; Han et al., 2000; Poolton et al., 2000; Schilles et al., 2001; Li,

25 2002; Polymeris et al., 2006; Oniya et al, 2012). Therefore, many attempts using TL and OSL sensitizations of

26 quartz were made to acquire paleo-firing temperatures. Sunta and David (1982) measured the sensitivity of the 110

$27{ }^{\circ} \mathrm{C}$ TL peak before and after the application of the pre-dose at different re-firing temperatures. They observed that

28 for pre-fired samples the ratio of the latter to the former remained constant until the firing temperature was attained.

29 The ratio began to increase significantly when the heating temperature was higher. Göksu et al. (1989) applied this

30 method to determine the ancient heat treatment of flint. However, Watson and Aitken (1985) observed that the

31 procedure developed by Sunta and David (1982) was not generally applicable. Their studies showed that the

32 sensitivity of the $110{ }^{\circ} \mathrm{C}$ and $230^{\circ} \mathrm{C}$ TL peak, respectively, may be associated with the maximum temperature the

33 quartz had experienced. Therefore, to some extent, the quartz can preserve a memory of its thermal history.

34 Polymeris et al. (2007) observed a relationship between TL and OSL sensitivities, and concluded that they could be

35 used to assess paleo-firing temperatures. It was reported that samples that have been heated to different

36 temperatures will display different in the plots of the sensitivity versus the re-firing temperature. However, most of

37 the studies were carried out on archaeological samples with small palaeo-doses. The potential for assessing the

38 paleo-firing temperatures based on luminescence sensitivity still needs further studies, particularly for geological

39 samples.

40 In this paper, we implemented experiments to acquire the relationship between the luminescence sensitivity

41 and firing temperatures. Methods determining the paleo-firing temperatures were established and applied to the

42 samples from a lava-baked layer in Datong, China. 


\section{$43 \quad$ 2. Samples and equipment}

44 Datong volcanic group is located in the Datong Basin in the northern part of China. More than 30 volcanoes

45 erupted in the area of about $900 \mathrm{~km}^{2}$. The volcanic eruptions in this region lie between Quaternary loess layers or

46 lacustrine sediments. Samples used in this study were collected from Yujiazhai profile. The lava in this area has an

47 age of about $300 \mathrm{ka}$ ( $\mathrm{Li}$ and Sun, 1984). The lacustrine sediments that have been baked by the lava flow had a

48 distinct red color compared with the unfired layer. Eight paleo-fired samples from the lava-baked layer and one

49 unfired sample beneath the baked layer (No: YJZC-7) were collected (Fig. 1). The unfired sample was used to heat

50 to different known temperatures for the investigation of the link between the luminescence sensitization and firing

51 temperatures in the laboratory. A portion of the unfired sample was used as a reference for comparisons.

52 Sample preparation was carried out under red light in the laboratory. All the samples were treated with $30 \%$

$53 \mathrm{H}_{2} \mathrm{O}_{2}$ and $30 \%$ HCL to remove the organic materials and the carbonates. They were treated with $30 \%$ fluorosilicic

54 acid for 5 days for the removal of feldspar contamination. After that, fine grains in the range 4-11 $\mu$ m were selected

55 according to Stoke's Law using acetone and deposited on stainless steel discs. The purity of the quartz was checked

56 with infrared stimulation (Li et al., 2002).

57 Luminescence measurements were performed using a Daybreak $2200 \mathrm{TL} / \mathrm{OSL}$ automatic system. A ${ }^{90} \mathrm{Sr} /{ }^{90} \mathrm{Y}$

58 beta source, delivering $\sim 0.05 \mathrm{~Gy} \mathrm{~s}^{-1}$, to quartz in stainless steel discs, was used for irradiation. The luminescence

59 signals were detected through two $3 \mathrm{~mm}$ U-340 filters in all observations. A SX2-10-13 muffle oven with the

maximum temperature of $1350{ }^{\circ} \mathrm{C}$ was used for heating the samples to different temperatures in the laboratory.

Throughout the paper, laboratory heated samples are referred to as fired samples, the temperatures as the firing 


\section{3 . Experimental procedures} heated to temperatures higher than $500{ }^{\circ} \mathrm{C}$. 
We applied the observations above to the paleo-fired samples. The $110^{\circ} \mathrm{C}$ TL peak sensitivity against re-firing

temperature of the paleo-fired samples are shown in Fig. $2 \mathrm{~b}$. All the curves had a peak at about $500{ }^{\circ} \mathrm{C}$. However, from field observations and studies, some of the samples were certainly heated to temperatures above $500{ }^{\circ} \mathrm{C}$.

Studies have shown that the TL sensitivity of quartz increases proportionally to the dose received before the thermal activation around $500{ }^{\circ} \mathrm{C}$, which is called pre-dose effect (Aitken, 1985). After being paleo-fired, the natural samples were naturally given large pre-doses during the process of sedimentation, before the re-firing in the

pre-dose effect affects the judgment on whether the paleo-firing temperature was above $500{ }^{\circ} \mathrm{C}$ or not. Therefore, we conclude that using the $110{ }^{\circ} \mathrm{C}$ TL sensitivity alone is not sufficient for indicating the paleo-firing temperatures,

because it is not only affected by the thermal history, but also the pre-dose effect (Li, 2002).

\section{$4.2110{ }^{\circ} \mathrm{C}$ TL sensitivity change rate against re-firing temperature}

Several studies have investigated the pre-dose effect in quartz (Zimmerman, 1971; McKeever, et al., 1985;

Yang and McKeever, 1990; Rendell, et al., 1994; Li, 2002). The pre-dose effect is particularly important for the paleo-fired samples because they are about 300 ka of age, of equivalent to a dose of 1300 Gy. The pre-dose effect gives rise to the different responses for the fired and paleo-fired samples as shown in results in section 4.1. We define the sensitivity change rate as the ratio of sensitivity at a temperature and the sensitivity of the temperature $100{ }^{\circ} \mathrm{C}$ lower of the same sample. For example, the sensitivity change rate at $600{ }^{\circ} \mathrm{C}$ is the ratio of the $110{ }^{\circ} \mathrm{C} \mathrm{TL}$ sensitivity at $600^{\circ} \mathrm{C}$ against the corresponding value at $500^{\circ} \mathrm{C}$. 
$110{ }^{\circ} \mathrm{C}$ TL sensitivity change rate versus re-firing temperature, but does not appear for samples that have been heated to more than $500{ }^{\circ} \mathrm{C}$.

The relationship between $110{ }^{\circ} \mathrm{C}$ TL sensitivity change rate and re-firing temperature for the paleo-fired

samples are shown in Fig. 3b. The curves have a peak at about $500^{\circ} \mathrm{C}$ for the samples with a distance of more than

about $100 \mathrm{~cm}$ from the lava, but the peak does not appear for the samples of less than about $100 \mathrm{~cm}$ from the lava,

except for a sample of $10 \mathrm{~cm}$ away from the lava. We deduce that the samples of less than about $100 \mathrm{~cm}$ from the

lava had been heated to more than $500{ }^{\circ} \mathrm{C}$, while the samples with a distance of more than about $100 \mathrm{~cm}$ from the

113 lava had not. The exception of the sample $10 \mathrm{~cm}$ from the lava will be discussed later.

\section{$4.3150{ }^{\circ} \mathrm{C}$ TL peak sensitivity against re-firing temperature}

The $150{ }^{\circ} \mathrm{C}$ TL peak sensitivity changes against re-firing temperature of fired samples are shown in Fig. 4a. A

large difference between the samples of the firing temperatures lower than $900{ }^{\circ} \mathrm{C}$ or above was observed. It has

than $900{ }^{\circ} \mathrm{C}$. No peak was observed for samples that were heated to $900{ }^{\circ} \mathrm{C}$ or above. This difference offered a means for distinguishing samples of the firing temperature below and above $900{ }^{\circ} \mathrm{C}$.

The $150{ }^{\circ} \mathrm{C}$ TL peak sensitivity changes against re-firing temperature of the paleo-fired samples are plotted in

Fig. 4b. The curves of the three samples near the lava, with the distance of 10, 40, $55 \mathrm{~cm}$ from the lava, do not have

122 a peak at about $900{ }^{\circ} \mathrm{C}$, which suggests that the samples have been heated to $900{ }^{\circ} \mathrm{C}$ or above. However, other samples (except one $128 \mathrm{~cm}$ away from the lava) have a peak at about $900{ }^{\circ} \mathrm{C}$, which implies that the samples have not been heated to $900{ }^{\circ} \mathrm{C}$.

\subsection{OSL $/ 150^{\circ} \mathrm{C}$ TL sensitivity against re-firing temperature}



curve of unfired sample (YJZC-7) before the re-firing temperature reaches the temperature the sample has been heated to. The two curves are overlapping with each other for the re-firing temperature above. The method is best suitable for samples fired $500{ }^{\circ} \mathrm{C}$ and above. the fired samples. overestimation of the firing temperature (Han et al., 2000).

\section{Discussions}

Our observations showed that the luminescence sensitization had a close relationship with the firing 
re-firing temperature can be used to estimate the paleo-firing temperatures of samples. The results obtained by using the three methods, which utilizing $110{ }^{\circ} \mathrm{C}$ TL sensitivity change rate, $150{ }^{\circ} \mathrm{C}$ TL sensitivity and the ratio of OSL $/ 150^{\circ} \mathrm{C}$ TL sensitivity, can be well compared with each other. The $110^{\circ} \mathrm{C}$ TL sensitivity is able to distinguish whether the sample has been fired to temperatures above $500{ }^{\circ} \mathrm{C}$ or not for the fired samples. However, the $110{ }^{\circ} \mathrm{C}$ by using the $110^{\circ} \mathrm{C} \mathrm{TL}$ sensitivity change rate, because the same pre-dose was applied for all re-firing temperatures of a sample. The $150^{\circ} \mathrm{C}$ TL sensitivity can be used to identify samples that have been heated to $\geq 900{ }^{\circ} \mathrm{C}$.

By using the ratio of OSL sensitivity to $150{ }^{\circ} \mathrm{C}$ TL sensitivity, we can estimate the paleo-firing temperature to which the sample has been heated. It can be obtained by comparing the OSL $/ 150{ }^{\circ} \mathrm{C}$ TL sensitivity versus re-firing temperature curve of the paleo-fired samples with that of the unfired sample. Both OSL and $150{ }^{\circ} \mathrm{C}$ TL sensitivity have also been affected by pre-dose effect ( $\mathrm{Li}$ and Chen, 2001). Both signals have different responses to thermal treatment. Ratio matching provides a way of demonstrating the thermal effect. We interpret that the OSL $/ 150{ }^{\circ} \mathrm{C}$ sensitivity ratio has combined both effects of OSL sensitivity and $150{ }^{\circ} \mathrm{C}$ TL sensitivity to re-firing temperatures. The combination can give a better resolution to the paleo-temperature of sample being heated. We deduce that the ratio of OSL $/ 150{ }^{\circ} \mathrm{C}$ TL sensitivity is dominated by the maximum temperature the sample had experienced. When the re-firing temperature is lower than the fired temperature, the maximum temperatures of the unfired and fired sample are different, so that the two lines are separating. When the re-firing temperature is higher than the fired temperature, the max temperatures of the unfired and fired sample are the same, so that the two lines are overlapping. Hence, the temperature can be constrained by comparing the curve of fired/peleo-fired samples and the unfired one. 
The peaks at curve of $110^{\circ} \mathrm{C} \mathrm{TL}$ and $150{ }^{\circ} \mathrm{C} \mathrm{TL}$ sensitivity against re-firing temperature indicate that the phase

changes shift from $\alpha$-quartz to $\beta$-quartz at $573{ }^{\circ} \mathrm{C}$, and $\beta$-quartz to $\beta$-tridymite at $870{ }^{\circ} \mathrm{C}$ occurred. The $110{ }^{\circ} \mathrm{C}$ TL sensitivity rate increases significantly to a peak around $500{ }^{\circ} \mathrm{C}$ for samples that have heated at less than $500{ }^{\circ} \mathrm{C}$, i.e. $\alpha$-quartz. For samples heated to $500-900{ }^{\circ} \mathrm{C}$, i.e. $\beta$-quartz, the $110{ }^{\circ} \mathrm{C}$ TL sensitivity change rates do not have a peak at about $500{ }^{\circ} \mathrm{C}$. For the sample that has been heated to above $900{ }^{\circ} \mathrm{C}$, i.e. $\beta$-tridymite, the $110{ }^{\circ} \mathrm{C} \mathrm{TL}$ sensitivity change rates have a peak around $500{ }^{\circ} \mathrm{C}$. This may explain the exception of the sample $10 \mathrm{~cm}$ away from the lava, which has similar behavior as samples heated below $500{ }^{\circ} \mathrm{C}$ in the $110{ }^{\circ} \mathrm{C}$ TL sensitivity change rate curves (Fig. 3b). The sample was heated to the highest temperature among the lava-baked samples, because it is the closest to the lava. The result from the OSL/150 ${ }^{\circ} \mathrm{C}$ TL sensitivity against re-firing temperatures suggests that this sample was heated to temperature above $1000{ }^{\circ} \mathrm{C}$. Similarly, the phase changes of quartz have been demonstrated in the $150{ }^{\circ} \mathrm{C}$ TL sensitivity. It is noted that quartz turns back to $\alpha$-quartz when it cooled to temperature of $573{ }^{\circ} \mathrm{C}$ or

lower. However, the sensitivity changes of quartz luminescence signals are irreversible. It was explained as a result of transferring holes from non-luminescence traps to luminescence traps (Zimmerman, 1971).

sensitivity change, because the same pre-dose is applied to the sample. Only the thermal effect will dominate the

$110{ }^{\circ} \mathrm{C}$ TL sensitivity change rate. Similarly, the ratio of OSL sensitivity and $150{ }^{\circ} \mathrm{C}$ TL would have small impacts of pre-dose, because the pre-dose effects affect both of the signals (Chen et al., 2000). Another advantage of using the ratio is that no normalization is required for the aliquots.

\section{Conclusions}


study. Significant changes in luminescence sensitivity happened at temperatures that are coincident with phase

change temperatures of the quartz.

\section{Acknowledgements}

We thank Prof. Yan-Chou Lu, Xu-Long Wang and Jin-Feng Liu for very helpful comments. We thank the

anonymous referee for the constructive comments. This work was supported by NSFC grant (40972208) and China

7033/12P and 17303014).

\section{References}

Aitken, M. J., 1985. Thermoluminescence Dating. Academic Press, London.

Bøtter-Jensen, L., Agersnap Larsen, N., Mejdahl, V., Poolton, N. R. J., Morris, M. F., McKeever, S. W. S., 1995. Luminescence 
211 Li, S-H., 2002. Luminescence sensitivity changes of quartz by bleaching, annealing and UV exposure. Radiation effects and defects in

212 solids, 157(3), 357-364.

213 Li, S-H., Chen, G., 2001. Studies of thermal stability of trapped charges associated with OSL from quartz. Journal of Physics D:

$214 \quad$ Applied Physics, 34(4), 493-498.

215 Li, S-H., Sun, J. M., Zhao, H., 2002. Optical dating of dune sands in the northeastern deserts of China. Palaeogeography, Palaeoclimatology, Palaeoecology, 181(4), 419-429.

McKeever, S. W., Chen, C. Y., Halliburton, L. E., 1985. Point defects and the pre-dose effect in natural quartz. Nuclear Tracks 10(4), 489-495.

Oniya, E. O., Polymeris, G. S., Tsirliganis, N. C., Kitis, G., 2012. Behavior of various Nigerian quartz samples to repeated irradiation and heating. Geochronometria, 39(3), 212-220.

Pinkerton, H., James, M., Jones, A., 2002. Surface temperature measurements of active lava flows on Kilauea volcano, Hawai' i. Journal of volcanology and geothermal research, 113(1), 159-176.

Polymeris, G., Kitis, G., Pagonis, V., 2006. The effects of annealing and irradiation on the sensitivity and superlinearity properties of the thermoluminescence peak of quartz. Radiation Measurements, 41(5), 554-564.

Polymeris, G., Sakalis, A., Papadopoulou, D., Dallas, G., Kitis, G., Tsirliganis, N., 2007. Firing temperature of pottery using TL and OSL techniques. Nuclear Instruments and Methods in Physics Research Section A: Accelerators, Spectrometers, Detectors and Associated Equipment 580 (1), 747-750. changes in natural quartz induced by high temperature annealing: a high frequency EPR and OSL study. Journal of Physics D: Applied Physics, 33(8), 1007. 
233 Schilles, T., Poolton, N. R. J., Bulur, E., Bøtter-Jensen, L., Murray, A. S., Smith, G., Riedi, P. C., Wagner, G. A., 2001. A of Physics D: Applied Physics, 34(5), 722. Measurements 10 (4-6), 517-520. 
Paleo-firing temperatures of the paleo-fired samples from the baked layer at Datong

\begin{tabular}{|c|c|c|c|}
\hline $\begin{array}{l}\text { Distance from the } \\
\qquad \operatorname{lava(cm)~}\end{array}$ & $\begin{array}{c}\text { Results from } 110{ }^{\circ} \mathrm{C} \\
\text { TL peak }\end{array}$ & $\begin{array}{c}\text { Results from } 150{ }^{\circ} \mathrm{C} \mathrm{TL} \\
\text { peak }\end{array}$ & $\begin{array}{c}\text { Results from OSL } / 150^{\circ} \mathrm{C} \\
\text { TL peak }\end{array}$ \\
\hline 10 & $<500{ }^{\circ} \mathrm{C}$ & $\geq 900^{\circ} \mathrm{C}$ & $>1000{ }^{\circ} \mathrm{C}$ \\
\hline 40 & $\geq 500^{\circ} \mathrm{C}$ & $\geq 900^{\circ} \mathrm{C}$ & $800^{\circ} \mathrm{C}$ \\
\hline 55 & $\geq 500^{\circ} \mathrm{C}$ & $\geq 900^{\circ} \mathrm{C}$ & $700^{\circ} \mathrm{C}$ \\
\hline 81 & $\geq 500^{\circ} \mathrm{C}$ & $<900^{\circ} \mathrm{C}$ & $550^{\circ} \mathrm{C}$ \\
\hline 97 & $\geq 500^{\circ} \mathrm{C}$ & $<900{ }^{\circ} \mathrm{C}$ & $500^{\circ} \mathrm{C}$ \\
\hline 107 & $<500^{\circ} \mathrm{C}$ & $<900{ }^{\circ} \mathrm{C}$ & $400^{\circ} \mathrm{C}$ \\
\hline 128 & $<500^{\circ} \mathrm{C}$ & $>900^{\circ} \mathrm{C}$ & $400^{\circ} \mathrm{C}$ \\
\hline 158 & $<500^{\circ} \mathrm{C}$ & $<900^{\circ} \mathrm{C}$ & $300^{\circ} \mathrm{C}$ \\
\hline
\end{tabular}

254

255

256

257

258

259

260

261

262

263

264

265 
Fig. 1. Location of samples in the profile and distances of samples from the lava above.

Fig. 2. $110^{\circ} \mathrm{C}$ TL sensitivity changes with re-firing temperatures for (a) the fired samples with different temperatures and (b) the paleo-fired samples from baked layer.

270

Fig. 3. $110^{\circ} \mathrm{C}$ TL sensitivity change rate with re-firing temperatures for (a) the fired samples with different temperatures and (b) the paleo-fired samples from the baked layer.

272 Fig. 4. $150{ }^{\circ} \mathrm{C}$ TL sensitivity changes with re-firing temperatures for (a) the fired samples with different temperatures and (b) the paleo-fired samples from the baked layer.

274 Fig. 5. OSL $/ 150^{\circ} \mathrm{C}$ TL sensitivity changes with re-firing temperatures of the fired samples with different temperatures.

275 Fig. 6. OSL $/ 150{ }^{\circ} \mathrm{C}$ TL sensitivity changes with re-firing temperatures of the paleo-fired samples from the baked layer.

276 Fig. 7. Relation between paleo-firing temperatures and distance from lava.

277 


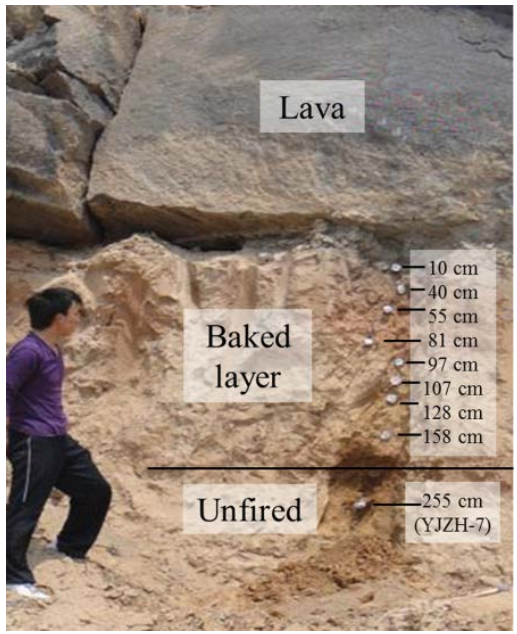

292

293 Fig. 1.

294

295

296

297

298

299

300

301

302

303 


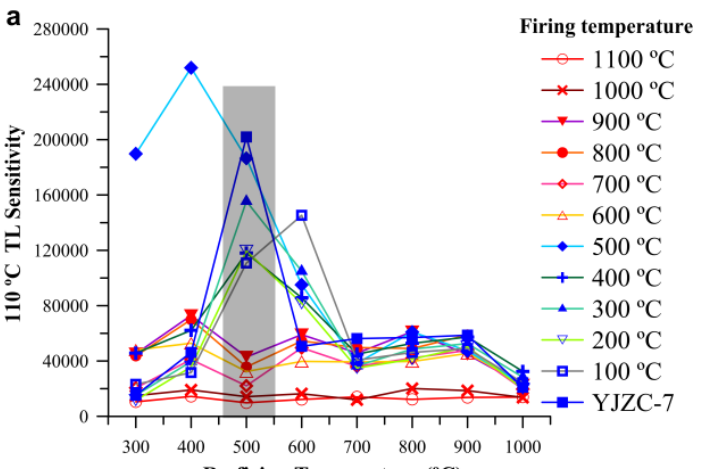
Re-firing Temperature $\left({ }^{\circ} \mathrm{C}\right)$

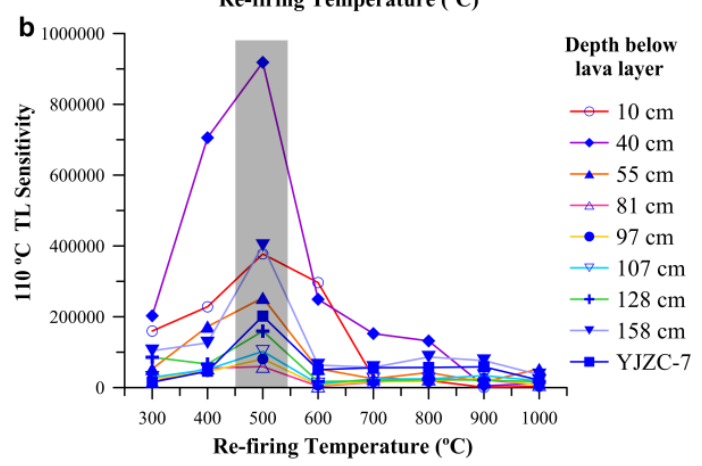

Fig. 2. 

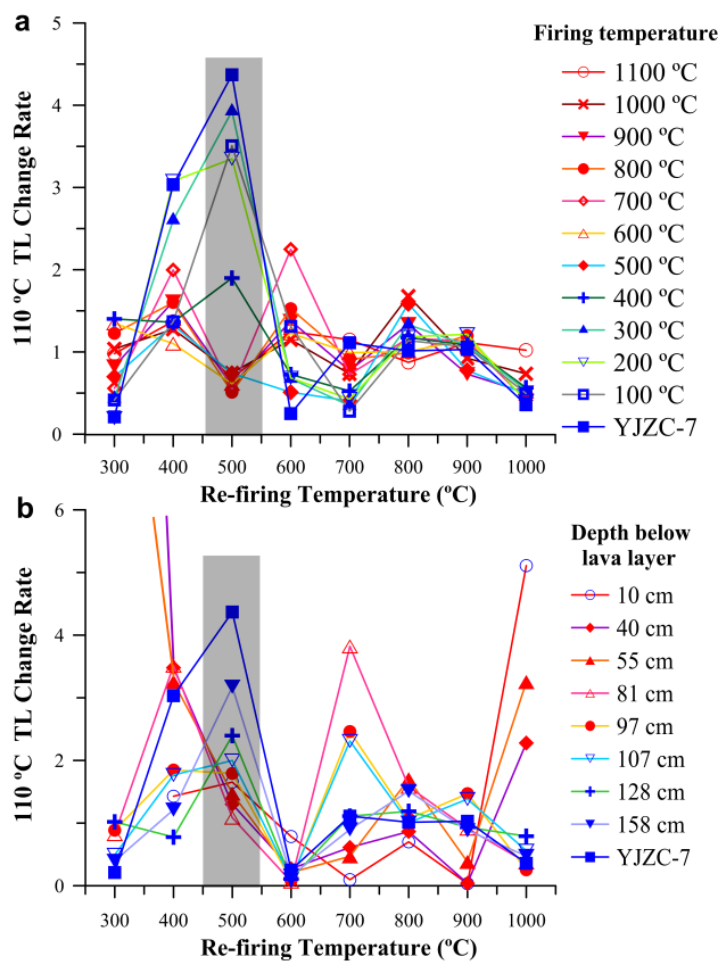

323 Fig. 3. 

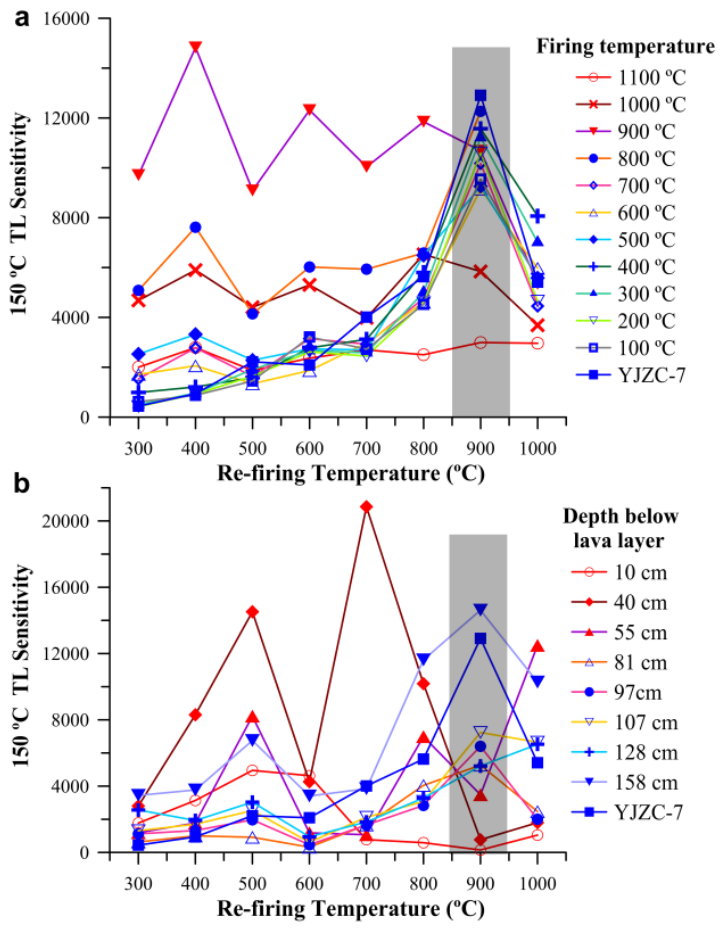

Fig. 4. 


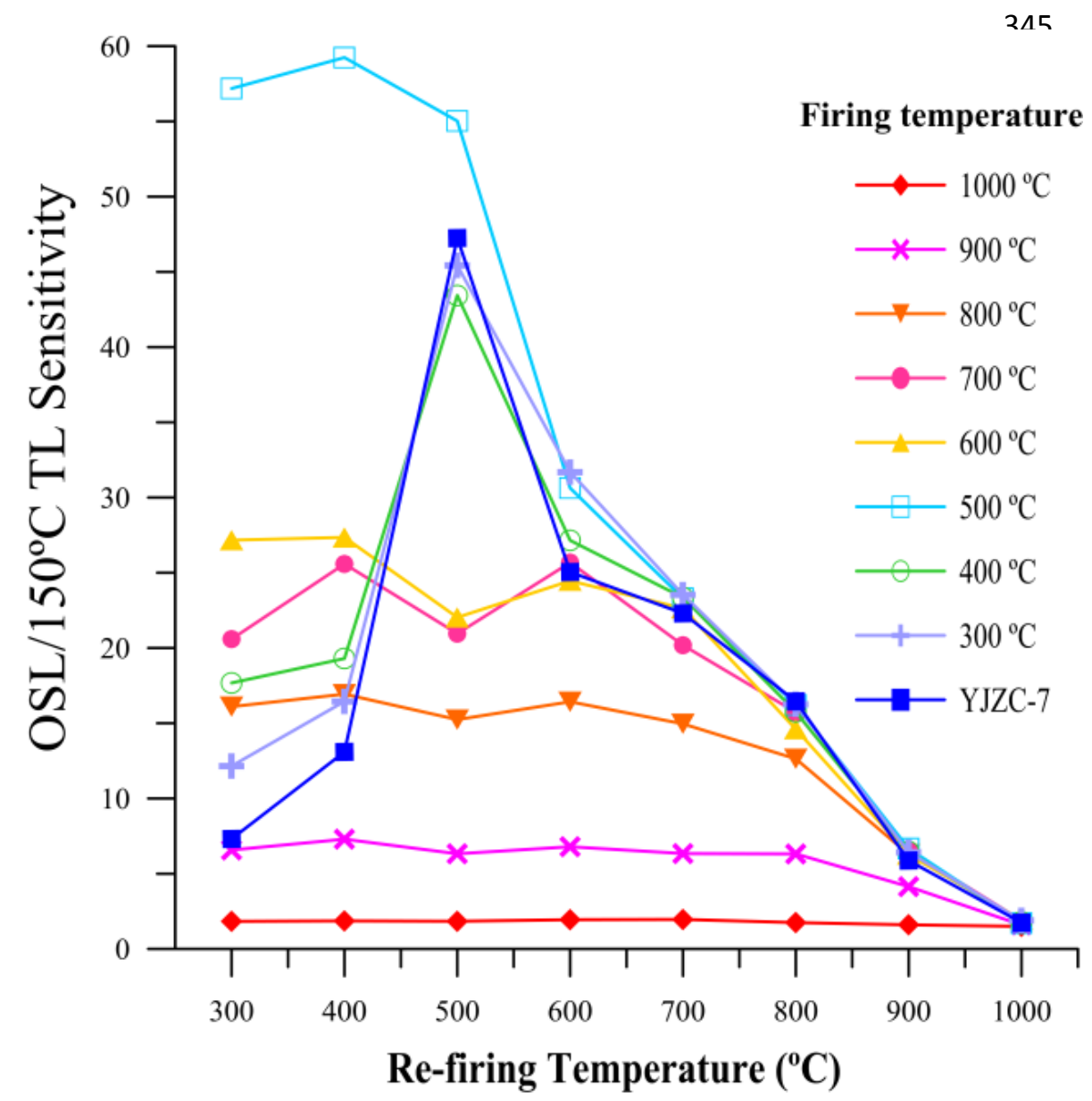

Fig. 5. 

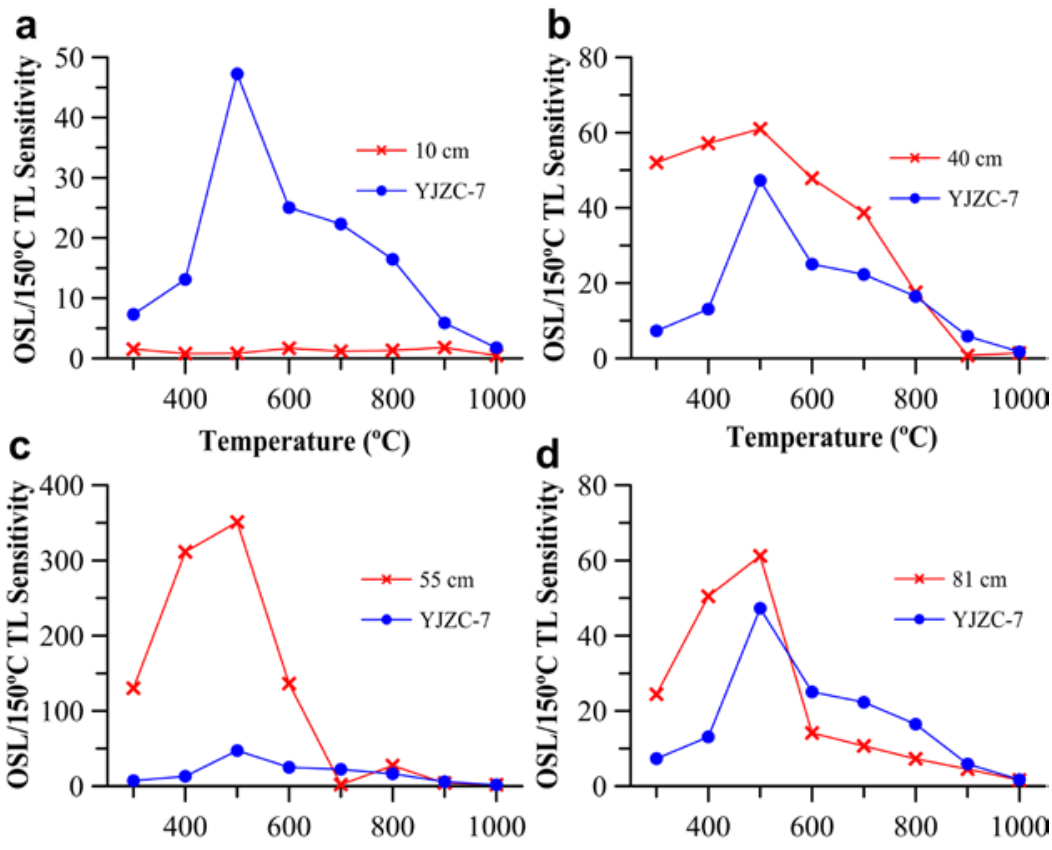

371

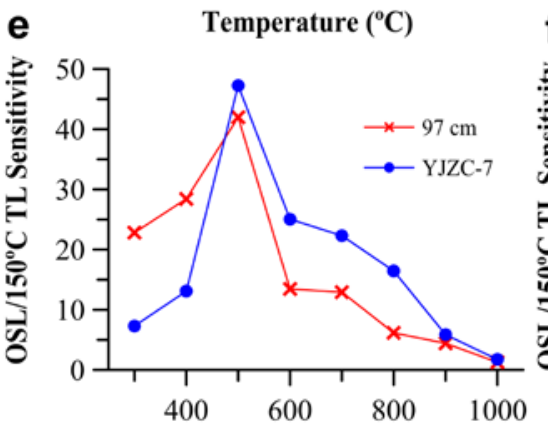

f Temperature $\left({ }^{\circ} \mathrm{C}\right)$

372

373

374

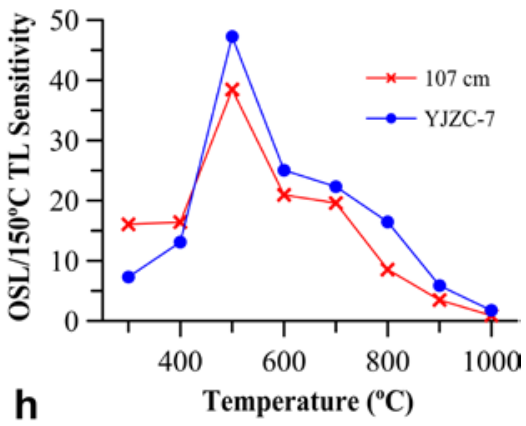

375
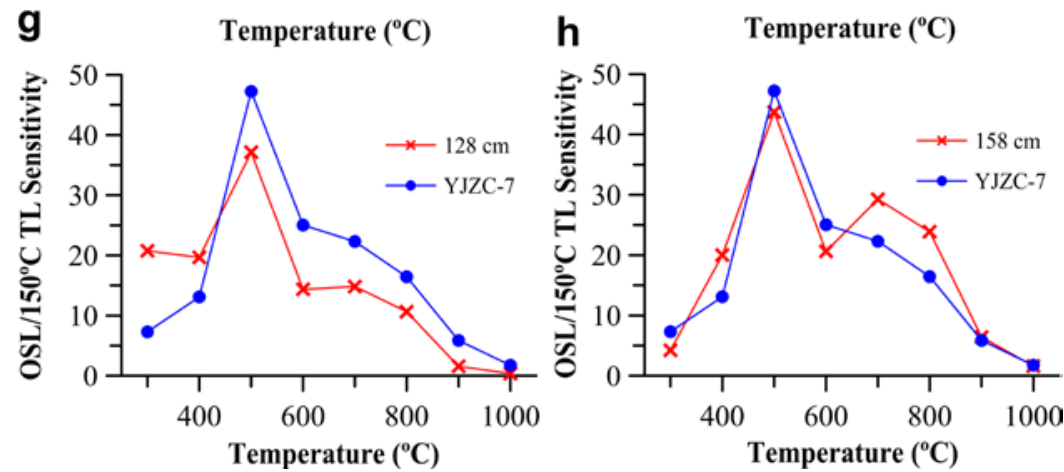

379

380

381

Fig. 6. 


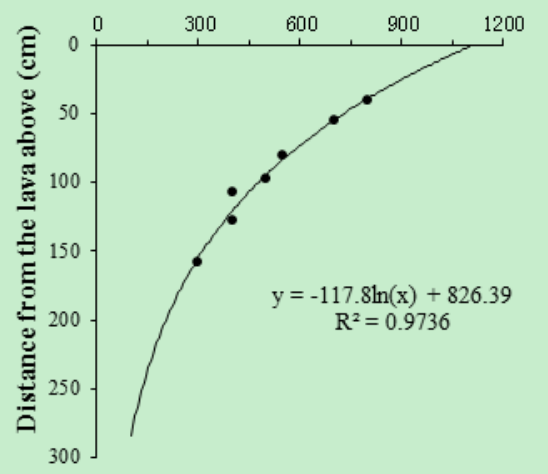

387

388

Fig. 7.

389 